total proper-motion distributions of $K$ stars to assess the proportions of giants at various apparent mag. nitudes.

All this information was then combined to yield the force of attraction of the Galaxy perpendicular to its plane, in the solar neighbourhood, as a function of distance from the plane. Finally, the total density of matter in the plane of the Galaxy near the Sun was calculated. The result is $9.2 \times 10^{-24} \mathrm{gm} . / \mathrm{cm} .{ }^{3}$, or 0.13 solar mass per cubic parsec. This is somewhat larger than obtained by Oort in 1932 .
Hill's work suffers from the disadvantage that for distances of more than 500 parsecs from the galactic plane the force obtained conflicts with the requirements of Poisson's law.

In another paper, J. H. Oort (Bull. Astron. Inst Netherlands, 15 , No. 494, 45; 1960) re-determines the force so that it is consistent both with the observational data assembled by Hill and with Poisson's law. He obtains $\mathbf{0} \cdot 15$ solar mass per cubic parsec for the density of matter in the solar neighbourhood, in excellent agreement with the result of Hill.

\title{
DWARF MISTLETOES
}

\begin{abstract}
A COMPREHENSIVE account of morphological aspects of the parasitism of dwarf mistletoes (Arceuthobium spp., Loranthaceae) on North American conifer species has been given by J. Knight (Univ. California Pub. Bot., 30, No. 5, 337; 1960). Some of the literature, terminology and main features of the development of these parasitic plants are critically reviewed and new observations submitted relating to $A$. americana and other species. At the time of penetration into the host the radicular apex loses its histological organization and becomes resolved into simple uniseriate filaments. Such filaments eventually become vascularized endophytic strands. It is possible that all radial sinkers and some aerial shoots may take their origin directly from uniseriate filaments.

All species of Arceuthobium may at maturity show a localized distribution pattern of the endophytic system and shoot emergence from the host. Such infections are in some cases associated with brooming phenomena of the tree. In addition, some species when infecting certain hosts induce a remarkable brooming response where the endophytic system keeps up with longitudinal host extension and where a great regularity of shoot emergence prevails. This is described as 'isophasic' parasitism.
\end{abstract}

There are recognizable differences in isophasic behaviour among species in which it occurs. These differences involve the position of mistletoe shoots in relation to host organs, dominance and precociousness of mistletoe shoots at the girdles, duration of reproductive activity, and so on. A mistletoe species causing an isophasic response on one host species may not do so on another ; similarly, a tree when infected by one mistletoe may form an isophasic broom, whereas infection by a second species may result in an entirely different type of parasitism. The isophasic capacity does not therefore reside solely in either host or parasite, but is the result of mutual interaction. The endophytic system is most extensively developed in isophasic brooms. In those of $A$. americana on Pinus contorta and of $A$. douglasii on Pseudotsuga menziesii, the ultimate filaments are present in the apical meristems of the host branches and probably remain there throughout the yearly growth-cycle. In the latter broom, an actual emergence of endophytic filaments takes place just above the youngest bud scales. The author suggests that the endophyte may be present in the apical meristem of the host branches of all isophasic brooms, and that such presence in the host apex is a corollary of regularity in shoot emergence.

\section{FACT AND FICTION ON THE BREEDING OF THE WANDERING ALBATROSS}

\author{
By DR. R. CARRICK, K. KEITH and Dr. A. M. GWYNN \\ Wildlife Section, Commonwealth Scientific and Industrial Research Organization, \\ Canberra, and Australian National Antarctic Research Expeditions, Melbourne
}

\begin{abstract}
THE reputation of the wandering albatross (Diomedea exulans) as a parent has suffered on occasion at the hands of the ornithologist, professional and amateur alike. The starvation theory held that the young albatross was fed from hatching in March until about June, and then deserted throughout the Antarctic winter while it subsisted on reserves of stored fat. Some writers state or imply that there is no resumption of parental feeding before the fledgling takes wing about December; others cite observations of feeding, or of fresh food in the nestling's stomach, in spring. The relevant evidence and opinions of succescive writers are :
\end{abstract}

1865. Hutton 1 stated that Harris at Kerguelen saw no adults between June and October, and no feeding from October onwards.

1866. Andersson ${ }^{2}$ quoted the opinion of a sealer that young albatrosses live on their own fat after being abandoned by the parents.

1891. Chapman ${ }^{3}$ stated that Fairchild observed albatrosses, nearly all young, on the islands below New Zealand in October, 1890, and concluded that the large full-grown chicks are abandoned and live on their own fat until they fly.

1905. Buller ${ }^{4}$ quoted Buckland, who visited islands to the south of New Zealand, to the effect that the 